\title{
ESTUDOS DE USUÁRIOS CONFORME O PARADIGMA SOCIAL DA CIÊNCIA DA INFORMAÇÃO: DESAFIOS TEÓRICOS E PRÁTICOS DE PESQUISA
}

\section{ESTUDIOS DE USUARIOS EN EL PARADIGMA SOCIAL DE LA CIENCIA DE LA INFORMACIÓN: DESAFÍOS TEÓRICOS Y PRÁCTICOS DE INVESTIGACIÓN}

\author{
Carlos Alberto Ávila Araújo - casalavila@yahoo.com.br \\ Professor Adjunto da Escola de Ciência da Informação da Universidade Federal \\ de Minas Gerais, UFMG. Doutor em Ciência da Informação e pós-doutorando na \\ Faculdade de Letras da Universidade do Porto-Portugal
}

\begin{abstract}
Resumo
Apresenta exemplos concretos de questões surgidas no âmbito de estudos de usuários da informação realizados conforme o paradigma social da Ciência da Informação. Em primeiro lugar mostra um quadro teórico dos estudos de usuários e os desafios contemporâneos que se colocam para o campo da pesquisa e do ensino. Utiliza exemplos de pesquisas realizadas no escopo da disciplina Usuários da Informação como forma de problematizar alguns aspectos relativos a essa aproximação. Conclui que a realização tais estudos pelo paradigma social acarreta novos problemas até então pouco discutidos no campo e reforça ainda a característica de ciência humana e social dos estudos de usuários da informação.
\end{abstract}

Palavras-chave

Estudos de usuário. Paradigma social. Ciência da Informação.

\section{INTRODUÇÃO}

Este artigo tem um objetivo prioritariamente didático. Trata-se de uma reflexão sobre um conjunto de experiências práticas de pesquisa no campo de estudos de usuários da informação aplicando-se conceitos relacionados ao que Capurro (2003) denominou "paradigma social" da Ciência da Informação (Cl).

Desde 2006, tenho ministrado a disciplina de Usuários da Informação. Na minha primeira oportunidade, vi-me desafiado a montar um programa de disciplina. Tive acesso a alguns programas anteriores existentes tanto na minha universidade como em outras. Contudo, optei por construir um programa 
próprio, enfatizando sobretudo o caráter prático da disciplina, isto é, a possibilidade dos alunos executarem, durante o semestre letivo, um estudo de usuários.

Meu ponto de partida, naquele momento, foi a ampla divisão existente na literatura do campo que apontava a existência de dois paradigmas nos estudos de usuários: o "tradicional" e o "alternativo". Na primeira vez em que ministrei a disciplina, portanto, estruturei-a com dois módulos. Num primeiro momento, após um conjunto de aulas teóricas e metodológicas, os alunos, divididos em grupos de quatro integrantes, iriam realizar um estudo de usuários da informação baseados na abordagem tradicional, priorizando métodos de coleta de dados quantitativos - preferencialmente, o questionário, contendo perguntas sobre identificação de perfil (idade, sexo, escolaridade, profissão ou outras que o grupo considerasse pertinentes) e de medição do comportamento informacional (fontes de informação mais utilizadas, grau de satisfação com os serviços de informação utilizados, tarefas para as quais necessitavam de informação, entre outras). Cada grupo escolhia um objeto empírico, que podia estar focado numa fonte ou sistema específico de informação (uma biblioteca, um arquivo, um museu, um centro de documentação, um portal na internet, um site específico), num grupo de usuários (alunos de determinado curso, funcionários de uma determinada empresa, sócios de algum clube) ou ainda em um assunto em particular (informação sobre saúde, política, esportes, etc.).

No segundo momento da disciplina, após uma nova bateria de aulas sobre teoria e metodologia, os grupos voltaram a campo para a realização da segunda etapa do trabalho, um estudo de usuários utilizando a abordagem alternativa, portanto privilegiando métodos de coleta de dados qualitativos (de preferência a entrevista), com o mesmo objeto empírico da etapa anterior (ainda que não fossem exatamente as mesmas pessoas que responderam ao questionário na etapa anterior, mas pessoas pertencentes ao mesmo universo). O objetivo aqui já não era buscar respostas "o quê", isto é, não interessava mais verificar onde o respondente marcava o " $x$ " num conjunto de opções dadas, mas, sim, buscar as justificativas para as respostas dadas na primeira etapa, buscar os "porquês".

Ao longo dos anos, contudo, e amadurecendo no contato com a literatura do campo da $\mathrm{Cl}$, percebi que essas duas abordagens não davam conta de uma série de questões relacionadas com a informação. Tal conjunto de questões foi muito bem elaborado por Capurro (2003), num trabalho em que o autor distingue não duas, mas três grandes formas de se estudar a informação na $\mathrm{Cl}$ : um modelo físico (semelhante ao paradigma "tradicional" de estudos de usuários), um modelo cognitivo (semelhante à abordagem "alternativa" de estudos de usuários) e um modelo social. Embora houvesse já alguns autores da $\mathrm{Cl}$ trabalhando na perspectiva deste terceiro modelo (HJORLAND, 2002; FROHMANN, 2008; RENDÓN ROJAS, 2005), no campo de usuários parecia haver ainda muito pouca produção científica.

Ainda assim, a questão do paradigma social da $\mathrm{Cl}$ foi sendo pouco a pouco incorporada na disciplina, de forma que, na segunda etapa do trabalho, os alunos já não iam a campo para realizar apenas um estudo conforme a 
abordagem "alternativa", de natureza cognitiva, mas um trabalho de certa forma híbrido, conjugando questões tanto da abordagem cognitiva quanto da social.

Durante a execução dos trabalhos, muitas dúvidas sobre como realizar as pesquisas e principalmente como analisar os dados encontrados proporcionaram momentos ricos na compreensão do que é e como se faz pesquisa com usuários da informação conforme o paradigma social da Cl. Há na área, contudo, pouca literatura sobre isso. Exatamente por esse motivo optou-se pela produção deste artigo. A ideia aqui é documentar um pouco desse processo, trazendo questões que surgiram tanto na elaboração dos instrumentos de coleta de dados quanto na forma de analisar os resultados encontrados e, ainda, no próprio tipo de resultado encontrado.

\section{O PANORAMA TEÓRICO}

A literatura científica sobre usuários da informação produzida até a década de 1970, no plano internacional, e até o começo da década de 1990, no Brasil, normalmente identifica esse campo como composto por estudos de uso de informação, de perfil de comunidades de usuários e de avaliação de sistemas e serviços de informação (FIGUEIREDO, 1994; RABELLO, 1980; LIMA, 1994; CUNHA, 1982; PINHEIRO, 1982). Trata-se de um campo desenvolvido ao longo de algumas décadas, com forte caráter empiricista, voltado para a aplicação de métodos prioritariamente quantitativos na busca de padrões e regularidades do comportamento dos usuários para 0 estabelecimento de leis "científicas" sobre o uso da informação.

Desde o final da década de 1970, diversos pesquisadores envolveramse na construção de modelos teóricos para entender melhor o processo pelo qual os usuários sentem necessidade e se engajam na busca e uso de informação. Sustentados por uma perspectiva cognitivista, autores como Belkin (1980), Wilson (1981), Dervin (1983), Taylor (1986), Ellis (1989) e Kuhlthau (1991) começaram a desenvolver modelos para a compreensão do "comportamento informacional" dos usuários. Esse conjunto de estudos recebeu o nome de "abordagem alternativa" (DERVIN; NILAN, 1986) por se contrapor ao outro modelo que entendia a informação como algo objetivo, dotado de sentido em si. Ao contrário, a abordagem alternativa buscava ver o que a informação é da perspectiva de quem a usa, do usuário. Essa perspectiva foi introduzida no Brasil na metade da década de 1990 (FERREIRA, 1995; MARTUCCI, 1997). Desde então, os vários trabalhos dedicados ao campo de usuários da informação (DIAS; PIRES, 2004; BAPTISTA; CUNHA, 2007) têm por hábito a apresentação do campo de usuários como sendo constituído por estas duas abordagens.

A evolução teórica do campo da Ciência da Informação como um todo, contudo, tomou um caminho um pouco diferente daquele vivenciado especificamente no campo dos estudos de usuários. Na sistematização de Capurro (2003), o campo da Cl teria vivenciado, desde seu surgimento, três grandes formas de se estudar a informação - que ele denomina "paradigmas". Assim, cruzando as duas matrizes apresentadas até aqui (a dos Estudos de Usuários e a da Cl), teríamos um quadro em que: 
a) A abordagem tradicional de estudos de usuários corresponderia ao paradigma físico de Capurro (2003). A informação é tida como algo objetivo, um objeto da realidade cujo sentido independe do usuário que se relaciona com ela, dotada de propriedades objetivas, isto é, inerentes (tais como relevância, exatidão, qualidade, etc.). Fazer estudos de usuários na perspectiva do paradigma físico consiste justamente em determinar as taxas de uso de cada tipo ou fonte de informação e correlacioná-las com os dados de perfil sóciodemográfico dos usuários. Tais estudos proporcionarão padrões previsíveis sobre o uso da informação que podem ser utilizados como mecanismos de avaliação dos serviços e sistemas de informação.

b) A abordagem alternativa de estudos de usuários corresponderia ao paradigma cognitivo de Capurro (2003). A informação é entendida como um recurso usado por um sujeito diante de uma situação de lacuna ou estado vazio de conhecimento. As diferentes formas como um sujeito percebe essa lacuna determinarão os tipos de ação desencadeadas por ele para buscar a informação necessária. Os diferentes usos previstos para a informação também intervêm no processo. Tipologias das necessidades, dos processos de busca e dos usos são pois os resultados dos estudos empíricos feitos nessa abordagem. Daí terem proliferado diferentes modelos para compreender o "comportamento informacional". Os modelos consistem de representações (muitas vezes visuais) do relacionamento entre os elementos (os tipos de necessidade, os tipos de busca, os tipos de uso) num determinado processo (o comportamento informacional). Esses modelos são construídos a partir de dados recolhidos da realidade (também numa perspectiva bem empiricista, embora aqui armada de um esquema teóricoconceitual mais elaborado) e a partir daí passam a servir como retratos analíticos para todas as situações.

c) O paradigma social descrito por Capurro (2003) não teria ainda uma manifestação muito nítida no campo de estudos de usuários. A maneira como diferentes pesquisadores têm desenvolvido esse paradigma, contudo, fornece importantes pistas de como poderia se dar sua aplicação nos estudos de usuários.

Uma primeira referência, nesse sentido, seria a proposta da "epistemologia social" de Shera (que serviu, aliás, de inspiração a Capurro para a denominação deste paradigma). Ainda nas décadas de 1960 e 1970, Shera propunha a criação de uma nova disciplina para estudar a inserção social do conhecimento humano, isto é, as interações entre os processos intelectuais (conhecimento produzido) e as atividades humanas e sociais. Trata-se, em sua visão, de uma disciplina que "deveria fornecer uma estrutura para a investigação eficiente de todo o complexo problema dos processos intelectuais das sociedades - um estudo pelo qual a sociedade como um todo procura uma relação perceptiva para seu ambiente total" (SHERA, 1977, p. 11).

Entre os autores contemporâneos que desenvolvem estudos nesta direção, Frohmann (2008), em sua teorização sobre os "regimes de 
informação", critica a abordagem alternativa por esta só considerar os sujeitos como seres isolados do mundo, como se cada sujeito que se relacionasse com a informação não estivesse envolto em uma série de dimensões políticas, econômicas, sociais e culturais. Justamente para ver esses atravessamentos e como eles condicionam toda e cada uma das situações de informação o autor desenvolveu seu conceito de "regime de informação".

Rendón Rojas (2005), na busca por uma abordagem realista-dialética da informação, recorre a Piaget para postular que o processo de conhecimento não é um fenômeno em que um sujeito com um "vazio" na mente busca algo para preencher esse vazio. O sujeito nunca é vazio, ele possui vários conhecimentos e também estruturas nas quais cada novo conhecimento se acomoda, não numa lógica cumulativa mas num processo interativo, de alterarse e ser alterado. Também a informação não é um "pacote" fechado que, apropriada pelo sujeito, ocupa um lugar na sua mente como se fosse uma peça de quebra-cabeças. Daí o autor recorrer a conceitos como "valor" e "imaginação" para o entendimento da informação.

Também Hjorland (2002) é um dos autores do paradigma social, o qual desenvolve a partir de sua abordagem de "análise de domínio". Partindo da ideia de "comunidades de discurso", o autor demonstra como nossos critérios são formados coletivamente, intersubjetivamente. Critérios estes não só sobre a realidade (o que é ou não real, o que é ou não belo, ético, etc.) como, também, critérios de julgamento da informação (boa ou ruim, completa ou incompleta, exata ou inexata). Somos conformados por consensos coletivos, os quais também não se impõem mecanicamente sobre nós - pois somos nós que os construímos.

Foi a partir desse panorama teórico que começou um interessante processo de reconstrução da disciplina Usuários da Informação. Os alunos foram instados a, mediante um conjunto de aulas e textos, formularem, na segunda etapa do trabalho de campo, uma abordagem que utilizasse contribuição tanto da abordagem alternativa de estudos de usuários quanto de questões trazidas pelo paradigma social da $\mathrm{Cl}$. Tanto o processo de analisar a primeira etapa da pesquisa de campo (o estudo com usuários a partir da abordagem tradicional) quanto os resultados específicos da segunda etapa proporcionaram momentos muito rico de problematização do que é estudar os usuários, das contribuições e dos limites de cada uma das possibilidades de estudo.

\section{OS AJUSTES NA DISCIPLINA}

O desafio teórico posto em questão se desmembrava em problemas de ordem prática. Desafiados a produzir estudos de usuários no modelo do paradigma social, frequentemente os alunos demandavam exemplos de estudos concretos realizados, ou ao menos bibliografia específica que se referisse a essa nova dimensão dos estudos. Tanto uma como outra eram escassas ou inexistentes.

Para o último caso, o da bibliografia, a solução encontrada foi recorrer a áreas próximas, que desenvolvessem abordagens em sintonia com os 
postulados do paradigma social da $\mathrm{Cl}$. As escolhas recaíram sobre três ramos particulares de estudo. O primeiro deles foi o Interacionismo Simbólico, corrente teórica surgida nos Estados Unidos ainda na primeira metade do século XX e que parte de três pressupostos: o de que os seres humanos agem com base nos significados dos objetos do mundo; de que esses significados são construídos nas interações; e de que estes significados passam por processos interativos (BLUMER, 1980). Ali onde o Interacionismo vê seres humanos e objetos, os estudos de usuários podem ver usuários e informação. Tal modelo teórico permite ver como os usuários são seres dinâmicos, ativos, e igualmente dinâmica é a informação.

O segundo modelo teórico usado foi a Etnometodologia, corrente que, ao contrário do que muitos pensam, não é uma metodologia especifica, mas o estudo ("logos") dos "etnométodos", isto é, os métodos cotidianos empregados pelas pessoas para dar sentido às coisas do mundo e agir sobre elas (COULON, 1985). Ao buscar esses métodos, os pesquisadores vinculados a essa corrente teórica conferem especial atenção às regras tácitas existentes e às formas como os sujeitos percebem essas regras e escolhem aplicá-las ou não no decurso das suas "práticas".

A terceira contribuição é da Antropologia Semiótica (GEERTZ, 1978), que estuda a cultura como um conjunto de teias de significado e analisa a ação humana como uma atuação em meio a essas teias. Assim, o estudo da ação humana jamais poderia se ater ao comportamento externamente observável seu estudo científico precisa incluir necessariamente o significado que o sujeito dá para a ação que desempenha. Um exemplo simples do autor: uma piscadela consiste no ato fisiológico de contrair as pálpebras. Mas a prática humana de piscar é muito mais do que o ato fisiológico: pode ser uma paquera, uma combinação, uma pequena mentira ou enganação, um tique nervoso, uma imitação de alguém que tem um tique nervoso... O mesmo ato fisiológico comporta diferentes práticas. O mesmo vale para o estudo do uso da informação. Usar uma fonte, pegar um livro na biblioteca, acessar um site, são todos comportamentos externamente observáveis. Para se ver 0 que efetivamente são, a "prática informacional" por detrás deles, é preciso estudar o significado dado pelo usuário que as usou. A essa análise científica, de ver o comportamento e o significado do comportamento para quem o executa, Geertz denomina "descrição densa".

Fazer a ligação entre os estudos de usuários e essas correntes teóricas serviu como importante base de inspiração para os alunos nas várias vezes em que a disciplina foi ofertada. Estudos baseados na Etnometodologia ou no Interacionismo Simbólico serviram como fonte de ideias para estudos sobre a informação, trazendo problemas e soluções que poderiam, por analogia, fertilizar o campo. Faltavam ainda, contudo, exemplos concretos de estudos de usuários da informação utilizando tais abordagens. Aqui se chega ao objetivo deste texto. Neste artigo se quer não trazer exemplos acabados de pesquisas utilizando tal abordagem, mas tão somente trazer fragmentos de trabalhos realizados justamente para se tensionar o campo dos estudos de usuários confrontado pelo paradigma social. 
A seguir são comentadas pequenas questões metodológicas e analíticas em alguns dos trabalhos desenvolvidos pelos alunos nas ocasiões de oferta da disciplina. Importante frisar que não se trata de pesquisas cientificamente realizadas (com projeto, problematização, pré-teste, tabulações rigorosas, transcrições de falas e aplicação de categorias de análise) mas, antes, experimentos didáticos realizados em sala de aula, no curto período de um semestre letivo. Por isso, interessa aqui menos os resultados efetivamente encontrados mas, sim, a maneira como alguns achados de pesquisa confrontam teórica e metodologicamente o campo.

Como os trabalhos dos alunos não são propriamente trabalhos científicos (sequer foram publicados, nem tiveram essa pretensão), optou-se aqui por não fazer referência indicativa a eles (autoria e título). Com isso, são também poupados de passar por um processo que poderia parecer uma injusta crítica ao mérito científico da sua produção - o que não é o caso, pois não é a qualidade dos trabalhos dos alunos que está sendo problematizada aqui, e sim os potenciais e limites explicativos do paradigma social da $\mathrm{Cl}$ aplicado ao campo dos estudos de usuários.

\section{A PREPARAÇÃO PARA A PESQUISA}

A primeira tarefa que os alunos precisam desempenhar na disciplina (além da leitura dos textos e acompanhamento das aulas, naturalmente) é a definição de um objeto empírico e, logo a seguir, a elaboração de um questionário, com limites entre 10 a 15 perguntas. Os grupos são orientados para tentarem ao máximo possível realizar apenas perguntas fechadas. Esse é um dos primeiros desafios do trabalho: prever as categorias de resposta, isto é, antecipar quais elementos presentes na realidade que representam as manifestações possíveis de um mesmo fenômeno.

$\mathrm{Na}$ elaboração de um questionário, tanto na disciplina de Usuários da Informação como em outras ocasiões, já tive mais de uma vez a oportunidade de escutar algo como "não usei teoria nenhuma, é um questionário objetivo, só para ver a realidade como ela é mesmo". Trata-se do típico argumento de quem imagina que é possível uma apreensão direta, "neutra", da realidade, tal como ela é em si, sem a interferência do sujeito que a conhece. Assim, a primeira aula da disciplina após a elaboração dos questionários serve tanto para discutir aspectos técnicos da elaboração de um questionário como, e principalmente, para problematizar a maneira como ele conforma determinados ângulos de percepção dessa realidade que será estudada. Dessa forma, o eixo das discussões não é buscar a "maneira certa" de coletar determinado dado - o objetivo da disciplina não é chegar a um receituário dos procedimentos corretos. O eixo é, sim, o de problematizar que aspectos da realidade podem ser compreendidos e de que forma cada uma das maneiras de os compreender traz resultados mais ou menos atentos à complexidade do fenômeno.

Um dos exemplos mais interessantes ocorreu com um grupo que queria estudar o hábito de leitura de jornais impressos. O grupo queria saber que jornais as pessoas liam, que tipo de jornais eram, e, depois, buscar as razões das escolhas. No primeiro protótipo de questionário, o grupo se deparou com 
uma questão: como listar todos os jornais existentes? Impossível. Era preciso categorizá-los de alguma forma. O grupo propôs, então, categorias de respostas: jornais tradicionais, jornais populares, jornais segmentados, jornais de bairro. Naturalmente, logo no primeiro dia de aula surgiu a polêmica: o que poderia ser considerado um jornal tradicional? E um jornal popular? O que um acha tradicional pode ser considerado popular para outro? Com a categoria "popular", o grupo queria se referir especificamente a dois jornais de Belo Horizonte, vendidos a um preço bem mais baixo que os demais, em formato tablóide e que, na visão deles, privilegiava temas sensacionalistas, como esportes, violência e mulheres. Não são, contudo, os únicos jornais da cidade que exploram esses assuntos.

Para resolver o problema, o grupo listou, após cada categoria, exemplos de nomes de jornais que se encaixavam em cada uma. A solução, na verdade, trouxe um outro problema. Ao dar o nome da categoria e do jornal, o grupo estava rotulando, de antemão, qual o significado de cada um dos jornais, direcionando desde já a opinião do respondente. Cada pessoa que fosse responder ao questionário encontraria, inicialmente, opções já dadas (jornal assim, do tipo assim; jornal assado, do tipo assado) com as quais poderia não concordar (achando que o jornal "assado" é do tipo "assim"), mas não teria como marcar a sua opção, pois as categorias estavam pré-definidas. Um outro grupo, fazendo um trabalho de natureza semelhante, sobre revistas, colocou como uma das opções "revistas sérias" e outra "revistas de fofocas".

Outro caso. Determinado grupo teve a ideia de avaliar como as pessoas se comportavam em relação a informações contendo humor e preconceito, buscando ver os tipos de aceitação e rejeição a determinados conteúdos. Ao montar os questionários, elaboraram uma pergunta sobre os tipos de preconceitos considerados intoleráveis e colocaram categorias como "racistas", "homofóbicos", "machistas" e "outros". Acreditaram que, assim, estavam previstas as categorias necessárias para os tipos de preconceitos existentes. Escutaram depois, como comentários ao questionário, respondentes alegando não apenas a ausência de determinado grupo ("pobres", "analfabetos" ou "obesos", por exemplo) mas também o significado dessa ausência. Ser colocado na categoria "outros" parecia indicar já uma outra forma de preconceito, como se o preconceito contra esses grupos fosse menos importante do que aquele vivido pelos outros grupos. Além disso, ao não dar essas opções para todos os respondentes, conduziam a uma "distorção" que seria sobrevalorizar as informações racistas, homofóbicas e machistas em relação às outras possíveis - que não eram citadas nominalmente no questionário aplicado.

Outro grupo elegeu como variável explicativa para uso de um determinado sistema de informação o grau de competência e habilidade no uso do computador. Para determinar esse grau, havia uma pergunta no questionário especificamente sobre esse tópico. Os questionários respondidos foram divididos em grupos conforme o tipo de resposta dada a essa questão, numa gradação de quatro níveis, para tabulação dos dados. Foram encontradas algumas tendências e várias discrepâncias. $\mathrm{Na}$ fase de entrevistas, pedindo aos usuários para falar sobre o grau de competência que possuem, os entrevistados expuseram uma variedade gigantesca de 
compreensões sobre o que significa "ser competente" ou "ter domínio de computador". Alguns com conhecimentos de vários recursos de vários softwares consideravam-se "incompetentes", enquanto outros que mal conheciam duas ou três funcionalidades de pouquíssimos programas às vezes se consideravam na categoria de maior domínio no uso dos recursos computacionais. Assim, a pergunta tal como formulada no questionário ajudou pouco na efetiva categorização dos usuários, já que disse mais respeito a como eles enxergam a sua competência do que propriamente qual é a sua competência em relação a certos parâmetros previamente definidos (pelo grupo) e em comparação uns com os outros.

Diversos outros grupos verificaram dimensões semelhantes, por exemplo, ao perguntarem nos questionários se as pessoas se consideravam bem ou mal informadas ou o grau de confiabilidade de determinada fonte de informação. Muitos exemplos poderiam ser explorados, mas, considerando os limites deste texto, parece ser suficiente parar aqui e começar com outra questão.

\section{DISCUSSÃO DE ALGUNS RESULTADOS}

A segunda etapa do trabalho de campo dos alunos consiste na realização de entrevistas com pessoas selecionadas no mesmo universo empírico da primeira etapa. Estas entrevistas são constituídas apenas de perguntas abertas, a partir de um roteiro produzido conforme resultados encontrados na primeira etapa e de cunho essencialmente compreensivo: focase nas compreensões dos usuários, nos seus entendimentos sobre seus próprios atos e da informação com a qual se relaciona. O trabalho final da disciplina consiste no cruzamento das análises realizadas com os dados das duas etapas.

No campo dos resultados encontrados nas várias pesquisas estão os elementos mais interessantes que trazem pontos para a discussão aqui proposta. Um dos grupos optou por realizar um trabalho bastante incomum em relação aos demais. Seu objetivo era verificar a maneira como alunos de doutorado e de mestrado usavam as fontes listadas nas referências ao final das respectivas teses e dissertações. Na primeira etapa da pesquisa, em lugar de aplicar questionários, optaram por fazer contagem de citações usando as referências - imaginando as referências como indicadores de uso da informação, isto é, se uma referência está lá na tese, é porque foi citada no corpo do texto, se foi citada, houve um uso para aquela fonte. Para tanto, os autores se respaldaram inclusive em autores que defendem a consideração de indicadores bibliométricos como indicadores de uso da informação (DIAS; PIRES, 2004). Mapeando um conjunto considerável de teses e dissertações, produziram uma base que apontava alguns autores que foram muito citados por vários alunos, uma grande quantidade citada por poucos e uma imensa quantidade citada por apenas um mestrando ou doutorando.

$\mathrm{Na}$ segunda etapa do trabalho, ao entrevistar os autores das teses e dissertações, surgiram diversos depoimentos, principalmente quando os 
entrevistados eram confrontados com a pergunta sobre qual o motivo do uso de cada uma das referências.

Muitos foram os relatos que distinguiam entre livros ou artigos que os haviam ajudado muitíssimo na pesquisa, foram essenciais, centrais para tudo, e outros que foram usados apenas para uma citação específica, casos em que o livro nem foi lido integralmente - na verdade, quase não foi lido. $O$ dado curioso da pesquisa é que, entre os dez autores das referências mais citadas, havia sete que foram classificados como autores de obras que pouco ou quase nada contribuíram para a pesquisa do mestrando ou doutorando.

$\mathrm{Na}$ verdade, muitos dos alunos estudados percebiam a importância de citar determinados autores para dar legitimidade ao seu trabalho, recorrendo ao chamado "recurso de autoridade". Como muitos fizeram isso, a taxa de uso das obras destes autores foi altíssima. Por outro lado, muitos autores cujos trabalhos foram extensamente utilizados pelos alunos (portanto, com um uso intenso por parte dos usuários) registraram taxas baixíssimas de citação no conjunto total das referências analisadas.

Trata-se de um exemplo muito claro de como os indicadores quantitativos podem "mascarar" um resultado que, efetivamente, se mostra muito diferente. Perguntados sobre as fontes de informação que mais utilizaram, efetivamente, em suas pesquisas, na etapa de entrevista, os mestrandos e doutorandos deram respostas nas quais os tais sete dos dez autores mais citados não figuravam. Ao confrontar os resultados da primeira etapa com os da segunda, os alunos ficaram chocados com as disparidades encontradas. Na primeira etapa, atribuir "um ponto" para cada fonte de informação utilizada por cada um dos mestrandos e doutorandos na listagem das referências conduzia a um resultado. Na segunda etapa, pedindo a eles que falassem sobre cada uma das fontes usadas "valorando a fonte" na perspectiva do usuário e do uso efetivamente dado, a listagem obtida das fontes mais relevantes era substancialmente diferente.

Outro grupo de alunos realizou uma pesquisa com usuários de informação sobre saúde, partindo de pessoas que tivessem tido recentes consultas com médicos e perguntando a elas como se deram suas práticas informacionais após essa consulta. Trata-se aqui de uma problemática bastante singular. A relação médico-paciente é caracterizada por uma relação hierárquica, de poder, muito delimitada. De um lado, está aquele que detém o conhecimento científico, o saber, o poder de tomar decisão, garantindo inclusive pela força da lei. De outro, está o paciente, não só tido como lugar desautorizado do saber, mas a quem inclusive se exige que não busque por conta própria saber, sob risco de cometer alguma ação equivocada.

A questão que provocava o grupo era saber se as pessoas buscavam, após as consultas, os diagnósticos proferidos pelos médicos e os tratamentos prescritos, informações sobre tudo isso, de forma a entender melhor o que estava acontecendo com elas - afinal, são os corpos e a saúde das próprias pessoas, que perdem na situação da consulta médica o poder de decisão sobre o que fazer com elas mesmas. Mais do que entender melhor, os alunos quiseram saber se as pessoas confrontavam informações diferentes e se 
tinham o hábito de questionar os médicos trazendo informações provenientes de outras fontes.

Nas entrevistas realizadas na segunda etapa, foram coletados depoimentos muito ricos sobre a maneira como os diferentes usuários "se armam" de informações para o momento da consulta médica. Afinal, a desigualdade de poder existe no momento do encontro entre o profissional e 0 paciente é também uma manifestação de desigualdade na posse de informações - embora não só, o médico tem, além de várias informações, uma formação, um treinamento, uma ética profissional, etc. Os alunos encontraram alguns tipos bem particulares de prática informacional. De um lado, aqueles que não buscavam outras fontes de informação além do médico (isto é, não se sentiam seguros ou autorizados a fazerem eles mesmos as buscas de informação), mas que, desconfiados da exatidão dos diagnósticos e tratamentos, realizavam consultas com outros médicos (em alguns casos, com vários) para confrontar as diferentes opiniões proferidas por eles. De outro lado, houve alguns respondentes que disseram sair do consultório médico e ir rapidamente buscar em outras fontes de informação (e principalmente na internet) dados que comprovassem a validade das informações recebidas no ato da consulta.

Um dado curioso foi perceber que, no caso de dados conflitantes (o usuário encontrar na internet dados contraditórios àqueles levantados pelo médico), a maior parte dos usuários "deixava para lá", isto é, não confrontavam o profissional da saúde nem aderiam totalmente ao que encontravam nas fontes de informação eletrônica. Antes, adotavam um comportamento de meio termo, seguindo as prescrições médicas, mas com um menor rigor. Ou seja, adotavam um comportamento resultado de uma confrontação de dados provenientes de diferentes fontes de informação em que nenhum dos dois lados era tido como totalmente confiável. Por fim, havia um grupo de entrevistados que, de posse de informações diferentes daquelas fornecidas pelo médico, voltava a estabelecer contato (normalmente por telefone) para apresentar suas novas questões e aguardar uma resposta, que poderia ser tanto uma confirmação do prognóstico já dado quanto uma adaptação pelo médico incorporando algo das novidades trazidas pelos entrevistados.

Ao consultar outras fontes além do médico, todos os usuários demonstraram preocupação com a qualidade destas fontes, alegando não confiar em "qualquer um" dos resultados apontados pelos motores de busca na internet. Alguns disseram basear seus julgamentos em revistas científicas. Houve ainda muitos casos de pessoas que disseram que familiares e conhecidos costumam ser fontes de informação também, mas muitos vistos mais como fontes complementares - de reforço de determinada ideia ou procedimento - do que como fontes primeiras para tomada de decisão sobre algo.

Em muitas entrevistas, ainda, apareceu fortemente uma impressão, por parte dos entrevistados, de certo "incômodo" e mal estar dos médicos nos casos em que os pacientes apareciam já na primeira consulta com um volume grande de informações sobre seus sintomas e possíveis medicamentos. Tais incômodos se justificam, em parte, pela apreensão dos profissionais da saúde 
de que as pessoas cometam erros na tentativa de resolverem por si os problemas mas são, também, reflexo da instabilidade causada pelo maior empoderamento dos pacientes, isto é, de sua maior condição de reverter parte do desequilíbrio de poder - um empoderamento que se dá pelo acesso à informação.

O próximo caso refere-se à busca de informações sobre política. A pesquisa dos alunos deu-se num período singular: as eleições municipais. No caso, em eleições que aconteceram numa condição muito curiosa. Um dos candidatos a prefeito era apoiado tanto pelo partido do presidente da república quanto pelo partido do governador do estado - dois partidos absolutamente rivais no plano nacional. Tal candidato era relativamente desconhecido de grande parte da população, e seu principal adversário também era alguém muito pouco conhecido. Diante de tal quadro, um grupo de alunos quis saber em que fontes de informação as pessoas buscavam elementos para tomar sua decisão quanto ao voto.

O confronto entre os dados da primeira etapa e da segunda etapa mais uma vez trouxe surpresa. Na primeira etapa, houve uma alta incidência para a importância de se buscar informação sobre os candidatos, de se acompanhar a cobertura informativa da mídia, de se ler os programas de governo ou assistir ao horário de propaganda eleitoral gratuita na televisão. Tais fontes foram avaliadas como muito importantes, mas as taxas de uso não atingiram os mesmos patamares - mas não ficaram tão distantes.

$\mathrm{Na}$ etapa de entrevista, os alunos pediam aos entrevistados para identificarem as fontes às quais tiveram acesso e o que encontraram nelas. Aparecia, aqui, muito pouco das fontes elencadas como as mais usadas na etapa dos questionários. Falando espontaneamente sobre as informações que haviam obtido dos candidatos, os entrevistados se referiam com muito mais desenvoltura a fragmentos de sites de conteúdo humorístico, charges, e-mails repassados por amigos ou conhecidos nas famosas "correntes", ou em páginas ou comunidades criadas em sites de relacionamentos. Mesmo no caso de sites de notícias consultados, os entrevistados se lembravam muito mais dos conteúdos postados nos comentários dos internautas do que naquilo que estava expresso no texto noticioso. Muitas vezes os entrevistados citavam fatos de campanha (algo feito ou dito por um ou outro candidato) e, quando perguntados de onde haviam obtido a informação, respondiam que era do comentário feito por alguém, e não do texto da imprensa ou do material de campanha do candidato. A importância das "fontes informais", ou do "colégio invisível", é então confirmada, tanto no sentido de fornecimento de informações para a tomada de decisão quanto, também, no de indicar outras fontes de informação. Uma boa parcela dos entrevistados comentou que outros usuários frequentemente faziam a indicação de matérias a serem lidas, blogs a serem acessados ou vídeos a serem assistidos sobre questões polêmicas relacionadas com a eleição.

Outro trabalho desenvolvido buscou analisar leitores de histórias em quadrinhos no ambiente universitário. Um dos resultados encontrados pelo grupo foi a existência de dois grandes grupos de usuários deste tipo de informação: aqueles orgulhosos de se assumir como leitores deste tipo de 
gênero cultural, que divulgam ou deixam transparecerem suas preferências para todos, mesmo em ambientes onde tal tipo de informação é considerada de pior qualidade ou infantilizada; e aqueles que gostam de tais produtos mas, percebendo a valoração que possuem no ambiente universitário, agem com discrição e evitam comentar sobre seu gosto. Em um ou outro caso, e essa é a questão importante, os grupos percebem claramente a existência de sentimentos negativos em relação aos quadrinhos. Há uma interpretação singular, por parte de uns e de outros, no sentido de dar a esses sentimentos coletivos um peso maior ou menor de tal forma que se decida por enfrentá-lo (ou enfrentar as conseqüências de expor um gosto contrário ao do valor consensualmente aceito) ou não se expor a ele.

Interpretações semelhantes foram encontradas por outros grupos. Um deles estudou pessoas que usam serviços de compras ou bancários por internet. Em meio às dimensões técnicas e tecnológicas envolvidas com o uso e o não uso (interface, competência no uso de informática, velocidade ou segurança da conexão) o grupo percebeu que existe um sentimento de medo relacionado com a segurança e o risco de clonagem ou cópia de senhas. Tais sentimentos eram provenientes tanto dos requisitos técnicos dos sistemas quanto de experiências vivenciadas pela própria pessoa ou por conhecidos, que conduziam em grande medida decisões relacionadas a usar ou não estes sistemas.

\section{CONSIDERAÇÕES FINAIS}

Os exemplos poderiam aqui se multiplicar. Existe uma riqueza imensa nos depoimentos colhidos pelos alunos e, principalmente, nas estratégias operadas por estes na tentativa de encontrar e aplicar corretamente as categorias de análise propostas. Assim, mais do que dar respostas definitivas, os casos apresentados acima trazem problemas, questões, percepções e representações.

Algumas vezes a validade científica de tais estudos é questionada. Muitos comparam o tipo de resultado encontrado em estudos assim com aqueles de estudos que apontam enfaticamente que " $73,4 \%$ dos engenheiros usam livros e $89,1 \%$ dos administradores usam internet" (para dar um exemplo fictício). O poder das estatísticas é sedutor e sua ideia de exatidão expressa nos números e nas casas decimais dá uma sensação de segurança, de que a realidade foi apreendida "tal como é". Pois essa postura esconde justamente o que está sendo conhecido e quem está conhecendo. Que engenheiros? De que local, ou época? Que livros? Todos os 73,4\% usam o livro igualmente?

Em ciências sociais e humanas, o poder explicativo do Positivismo (a aplicação dos métodos das ciências exatas aos fatos humanos) já vem sendo colocado em xeque há décadas (MINAYO, 2000; DEMO 1992; MOSTAFA; LIMA; MARANON, 1992). Nos estudos de usuários, também já se comprovou seu relativo poder explicativo (LIMA, 1994; CHOO, 2003) principalmente porque uma série de descobertas empiricamente descobertas não se confirmavam em estudos seguintes (RABELLO, 1980), gerando uma massa de 
dados acumulados com os resultados os mais díspares entre si. Ainda assim, serviram para descrever, de algum modo, alguma realidade.

Os modelos de comportamento construídos também possuem seu valor explicativo, permitem visualizar um processo, estabelecer tipos de manifestação. Geralmente, contudo, retratam situações restritas no tempo e no espaço, e acabam engessando as formas de apreensão de outras realidades em pesquisas posteriores.

Não se trata, pois, de comparar os paradigmas para determinar qual o melhor. Cada modelo teórico apreende alguns aspectos da realidade e deixa de fora outros. Aquilo que não era respondido pelo paradigma físico da $\mathrm{Cl}$ tornou-se parte das preocupações do paradigma cognitivo. Igualmente, o paradigma social surgiu para iluminar questões não compreendidas pelo cognitivo. No caso dos estudos de usuários da informação, o paradigma social vem para problematizar aspectos de como a definição de critérios de qualidade e valor da informação é construída socialmente, e atravessada por fatores históricos, culturais, políticos, sociais e econômicos.

"Mas quando responderemos 'tudo' sobre os usuários da informação?" é uma pergunta comum na sala de aula. Para respondê-la, gosto de usar uma breve passagem de Geertz, a qual evoco agora para fechar este texto. Conta Geertz (1978), com sua habitual elegância, de certa ocasião em que, estando na Índia, viu-se diante de uma compreensão mitológica em que a Terra seria sustentada por um elefante, e este sobre o casco de uma tartaruga. $O$ antropólogo, claro, pergunta: "E a tartaruga?". Ao que escuta, como resposta, de que esta está sobre outra tartaruga, que está sobre outra, e assim indefinidamente.

Assim são os problemas relativos à realidade humana e social. Não se chega ao fundo da questão, a uma resposta cabal e absoluta, quando o objeto estudado é também sujeito, dotado de vontade, historicidade e condutor do seu destino. O máximo que se pode fazer é promover novas e mais profundas incursões, encontrando sempre novos elementos explicativos, incorporando novas questões e aspectos que compõem a realidade explicada. Os usuários da informação, como seres humanos que são, compartilham dessa característica. Assim se constitui o limite e a riqueza do seu estudo científico.

\section{REFERÊNCIAS}

BAPTISTA, Sofia; CUNHA, Murilo. Estudo de usuários: visão global dos métodos de coleta de dados. Perspectivas em Ciência da Informação, Belo Horizonte, v. 12, n. 2, p. 168-184, maio/ago. 2007.

BELKIN, Nicholas. Anomalous states of knowledge as a basis for information retrieval. The Canadian Journal of Information Science, Toronto, v. 5, p. 133$143,1980$. 
BLUMER, Herbert. A natureza do interacionismo simbólico. In: MORTENSEN, C. D. Teoria da comunicação: textos básicos. São Paulo: Mosaico, 1980, p. 119-138.

CAPURRO, Rafael. Epistemologia e ciência da informação. In: ENCONTRO NACIONAL DE PESQUISA EM CIÊNCIA DA INFORMAÇÃO, 5., 2003, Belo Horizonte. Anais... Belo Horizonte: ENANCIB, 2003.

$\mathrm{CHOO}$, Chun Wei. Como ficamos sabendo: um modelo de uso da informação. In: A organização do conhecimento: como as organizações usam a informação para criar significado, construir conhecimento e tomar decisões. São Paulo: SENAC, 2003. p. 63-120.

COULON, Alain. Etnometodologia. Petrópolis: Vozes, 1985.

CUNHA, Murilo. Metodologias para estudo dos usuários de informação científica e tecnológica. Revista de Biblioteconomia de Brasília, v. 10, n. 2, p. 519, jul./dez. 1982.

DEMO, Pedro. Metodologia científica em ciências sociais. São Paulo: Atlas, 1992.

DERVIN, Brenda. An overview of sense-making research: concepts, methods and results to date. In: ANNUAL MEETING OF THE INTERNACIONAL COMMUNICATION ASSOCIATION, 1983. Anais... Dallas: International Communication Association, 1983.

DERVIN, Brenda; NILAN, Michael. Information needs and uses. Annual Review of Information Science and Technology, Chicago, v. 21, p. 03-33. 1986.

DIAS, Maria Matilde; PIRES, Daniela. Usos e usuários da informação. São Carlos: Edufscar, 2004.

ELLIS, David. A behavioural approach to information retrieval design. Journal of Documentation, Londres, v. 45, n. 3, p. 171-212, 1989.

FERREIRA, Sueli Mara Soares Pinto. Novos paradigmas e novos usuários de informação. Ciência da informação, Brasília, v. 25, n. 2, maio/ago. 1995.

FIGUEIREDO, Nice Menezes de. Estudos de uso e usuários da informação. Brasília: IBICT, 1994.

FROHMANN, Bernd. O caráter social, material e público da informação. In: FUJITA, M.; MARTELETO, R.; LARA, M. (Org.). A dimensão epistemológica da ciência da informação e suas interfaces técnicas, políticas e institucionais nos processos de produção, acesso e disseminação da informação. São Paulo: Cultura Acadêmica; Marília: Fundepe, 2008. p. 19-34.

GEERTZ, Clifford. A interpretação das culturas. Rio de Janeiro: Zahar, 1978. 
HJORLAND, Birger. Domain analysis in information science. Journal of Documentation, Londres, v. 58, n. 4, 2002, p. 122-162.

KUHLTHAU, Carol. Inside the search process: information seeking from the users perspective. Journal of the American Society for Information Science, Nova lorque, v. 42, n. 5, p. 361-371, 1991.

LIMA, Ademir Benedito Alves de. Aproximação crítica à teoria dos estudos de usuários de bibliotecas. Londrina: EMBRAPA-CNPSo; Brasília: EMBRAPA-SPI, 1994

MARTUCCI, Elisabeth Márcia. A abordagem sense-making para estudo de usuário. Porto Alegre: ABEBD, 1997.

MINAYO, M.C. O desafio do conhecimento: pesquisa qualitativa em saúde. São Paulo: Hucitec, 2000.

MOSTAFA, Solange; LIMA, Ademir; MARANON, Eduardo. Paradigmas teóricos da biblioteconomia e ciência da informação. Ciência da informação, Brasília, v. 21, n. 3, set./dez. 1992, p. 216-222.

PINHEIRO, Lena. Usuários-informação: o contexto da ciência e tecnologia. Rio de Janeiro: LTC, 1982.

SHERA, Jesse. Epistemologia social, semântica geral e biblioteconomia. Ciência da Informação, Rio de Janeiro, v. 6, n. 1, p. 09-12, 1977.

RABELLO, Odilia Clark. Análise do campo de conhecimento relativo a usuário de biblioteca. 1980. 93f. Dissertação (Mestrado em Administração de Bibliotecas)-Universidade Federal de Minas Gerais, Belo Horizonte, 1980.

RENDÓN ROJAS, Miguel Ángel. Relación entre los conceptos: información, conocimiento y valor. Semejanzas y diferencias. Ciência da Informação, Brasília, v. 34, n. 2, p. 52-61, maio/ago. 2005.

TAYLOR, Robert. Value-added processes in information systems. Norwood: Ablex, 1986.

WILSON, Tomas Daniel. On user studies and information needs. Journal of Documentation, Londres, v. 37, n.1, p. 03-15. 1981.

\section{Title}

Information user studies in the social paradigm of Information Science: theoretical and practical issues

\section{Abstract}


It presents some concrete examples of issues raised in information user studies according to the social paradigm of Information Science. Firstly, a theoretical framework of user studies and the contemporary challenges facing both the research and teaching practices in this topic are presented. Secondly, some examples of researches conducted within the scope of the discipline Information Users are provided. It concludes that studies by the light of social paradigm pose new problems never before discussed in the field and reinforce the human and social science nature of information user studies.

Keywords: User studies. Social paradigm. Information Science.

\section{Título}

Estudios de usuarios en el paradigma social de la Ciencia de la Información: desafíos teóricos y prácticos de investigación

\section{Resumen}

Se presentan ejemplos concretos de las cuestiones planteadas en los estudios de usuarios de la información realizados bajo el paradigma social de la Ciencia de la Información. En primer lugar muestra un marco teórico de los estudios de usuarios y los desafíos actuales que se plantean para el campo de la investigación y de la enseñanza. Utiliza ejemplos de investigaciones realizadas en el ámbito de la disciplina Usuarios de la Información con el fin de discutir algunos aspectos relativos a ese enfoque. Concluye que la realización de tales estudios por medio del paradigma social plantea nuevos problemas hasta ahora poco discutidos en el campo y refuerza todavía la característica de ciencia humana y social de los estudios de usuarios de la información.

\section{Palabras-clave}

Estudios de usuarios. Paradigma social. Ciencia de la Información.

Recebido em: 26/09/2010

Aceito em: 01/02/2011 